\title{
Serum Neurofilament Light Polypeptide is a Biomarker for Inflammation in Cerebrospinal Fluid Caused by Fine Particulate Matter
}

\author{
Ta-Chih Hsiao" ${ }^{\#}$, Jungshan Chang ${ }^{2 \#}$, Jia-Yi Wang ${ }^{2,3}$, Dean Wu ${ }^{4,5}$, Kai-Jen Chuang ${ }^{6,7}$, \\ Jen-Kun Chen ${ }^{8}$, Tsun-Jen Cheng ${ }^{9}$, Hsiao-Chi Chuang ${ }^{10,11,12^{*}}$
}

${ }^{1}$ Graduate Institute of Environmental Engineering, National Taiwan University, Taipei 106032, Taiwan

${ }^{2}$ Graduate Institute of Medical Sciences, College of Medicine, Taipei Medical University, Taipei 11031, Taiwan

${ }^{3}$ Department of Physiology, School of Medicine, College of Medicine, Taipei Medical University, Taipei 11031, Taiwan

${ }^{4}$ Department of Neurology, Shuang Ho Hospital, Taipei Medical University, New Taipei City 23561, Taiwan

${ }^{5}$ Department of Neurology, School of Medicine, College of Medicine, Taipei Medical University, Taipei 11031, Taiwan

${ }^{6}$ School of Public Health, College of Public Health, Taipei Medical University, Taipei 11031, Taiwan

${ }^{7}$ Department of Public Health, School of Medicine, College of Medicine, Taipei Medical University, Taipei 11031, Taiwan

${ }^{8}$ Institute of Biomedical Engineering and Nanomedicine, National Health Research Institutes, Miaoli 35053, Taiwan

${ }^{9}$ Institute of Occupational Medicine and Industrial Hygiene, College of Public Health, National Taiwan University, Taipei 10617, Taiwan

${ }^{10}$ School of Respiratory Therapy, College of Medicine, Taipei Medical University, Taipei 11031, Taiwan

${ }^{11}$ Cell Physiology and Molecular Image Research Center, Wan Fang Hospital, Taipei Medical University, Taipei 11696,

Taiwan

${ }^{12}$ Division of Pulmonary Medicine, Department of Internal Medicine, Shuang Ho Hospital, Taipei Medical University, New Taipei 23561, Taiwan

\begin{abstract}
Epidemiological and toxicological evidence indicates that fine particulate matter $\left(\mathrm{PM}_{2.5}\right.$, particulate matter $<2.5 \mu \mathrm{m}$ in aerodynamic diameter) causes cardiopulmonary toxicity; however, its neurotoxic effects remain unclear. The objective of this study was to investigate the role of the neurofilament light (NEFL) serum polypeptide in neurotoxicity. 6-month-old male Sprague Dawley (SD) rats were exposed to traffic-related $\mathrm{PM}_{1}\left(<1 \mu \mathrm{m}\right.$ in aerodynamic diameter; $\left.16.3 \mu \mathrm{g} \mathrm{m}^{-3}\right)$ and gaseous pollutants (via high-efficiency particulate air, HEPA) for 3 and 6 months through a whole-body exposure system. According to our observations, the levels of interleukin (IL)-4, IL-10, and tumor necrosis factor (TNF)- $\alpha$ in the serum of the rats significantly increased $(p<0.05)$ after 3 months of exposure to $\mathrm{PM}_{1}$, whereas that of NEFL polypeptide significantly increased $(p<0.05)$ after 3 and 6 months of exposure. Additionally, increases in the IL-2, IL- 6 , IL-10, IL-17a, TNF- $\alpha$, and interferon (IFN)- $\gamma$ levels after 3 and/or 6 months of exposure to this pollutant $(p<0.05)$ were observed in the cerebrospinal fluid (CSF). In terms of their respective levels, the IL-6 correlated well with the CSF IL-2 and IL-10; the TNF- $\alpha$ correlated well with the CSF IL-6, IL-17a, TNF- $\alpha$, and IFN- $\gamma$; and the NEFL polypeptide correlated well with the CSF IL-2, IL-4, IL-6, IL-10, IL-17a, TNF- $\alpha$, and IFN- $\gamma$. In summary, systemic neuroinflammatory and immune responses in rats occurred after chronic exposure to $\mathrm{PM}_{1}$. Hence, NEFL polypeptide in serum may be a suitable biomarker for neurotoxicity caused by chronic exposure to this pollutant.
\end{abstract}

Keywords: Air pollution; Central nervous system; Neurotoxicity; Oxidative stress; Particulate matter.

\section{INTRODUCTION}

Neurodegenerative diseases are emergent chronic diseases in aging populations nowadays. According to the National Institute of Neurological Disorders and Stroke, there are

\footnotetext{
\# The authors contributed equally in this work.

* Corresponding author.

Tel.: +886-2-27361661; Fax: +886-2-27391143

E-mail address: r92841005@ntu.edu.tw
} more than 600 neurodegenerative disease, which affect approximately 50 million Americans each year (Brown et al., 2005). In Taiwan, the average age-standardized prevalence of neurodegenerative diseases, such as Parkinson's disease (PD), per 100,000 population were 84.8 in 2004 and 147.7 
in 2011, representing a 7.9\% annual increase (Liu et al., 2016). Notably, accumulating epidemiological evidence indicates that pulmonary exposure to particulate air pollution is associated with increased risks of neurodegenerative diseases (Power et al., 2011). For example, exposure to high levels of coarse particulate matter $\left(\mathrm{PM}_{2.5-10}\right.$, particulate matter with an aerodynamic diameter of $2.5-10 \mu \mathrm{m})$ and fine particulate matter $\left(\mathrm{PM}_{2.5}\right)$ is associated with increased risks of cognitive decline (Weuve et al., 2012). Increased risks of neurodegenerative diseases such as PD were associated with chronic exposure to air pollution (Kioumourtzoglou et al., 2016; Ritz et al., 2016). It is worth noting that the effects of air pollution on the overall risk of neurodegenerative disease may be considerably higher than previously thought (The Lancet Neurology, 2018). Therefore, understanding the impacts of PM on the initiation of neurodegenerative disease is an urgent public health issue.

Our previous studies observed that chronic exposure to traffic-related air pollution caused cerebral edema and brain impairment in adult rats (Shih et al., 2018). Oxidative stress and inflammation occurred in rat brains after PM exposure (Bai et al., 2018; Li et al., 2019), which led to central nervous system (CNS) impairment. The neuroinflammation could be due to microglia activation by ambient particulate matter (PM) exposure (Bai et al., 2019a). Also, exposure of PM caused the formation of amyloid- $\beta$ (A $\beta$ ) plaque (Cacciottolo et al., 2017) as well as tau accumulation (Bai et al., 2018; Calderon-Garciduenas et al., 2018) in the brain. Exposure to traffic-related air pollution disrupted the brain's microvascular integrity in a high-fat diet animal model (Suwannasual et al., 2018). Oxidative-inflammatory responses may cause the extracellular accumulation of fluid due to increased permeability of the blood-brain barrier (BBB). However, there are no biomarkers available to assess and evaluate conditions of the brain environment after PM exposure.

Cerebrospinal fluid (CSF) is produced by specialized ependymal cells in the choroid plexuses of the ventricles of the brain, and it is present in the brain and spinal cord. Clinically, CSF is used to represent the condition of the brain for diagnoses (Molinuevo et al., 2014; Vogelgsang et al., 2018). Increasing numbers of studies have investigated the effects of air pollution on the brain based on CSF evidence. For example, a series of studies indicated that exposure to air pollution increased CSF inflammatory markers such as interleukin (IL)-6 and IL-2 (Calderon-Garciduenas et al., 2013), which are associated with increased risks of Alzheimer's disease (AD) and PD (Calderon-Garciduenas et al., 2016). The effects on the brain were more significant due to smaller PM such as ultrafine PM (Gonzalez-Maciel et al., 2017).

Increasing evidence revealed that proteins from the CSF and serum are able to improve clinical diagnoses for neurodegenerative diseases (Pereira et al., 2017). The neurofilament light (NEFL) polypeptide, for example, was observed to be present in both the CSF and the serum, and its levels between the CSF and serum were well correlated (Norgren et al., 2003). Clinically, the serum NEFL polypeptide is considered a marker of brain damage and ongoing disease activity (Kuhle et al., 2017). However, expression of the NEFL polypeptide in the serum after exposure to $\mathrm{PM}_{2.5}$ remains unclear. The objective of this study was to investigate expression of the NEFL polypeptide in serum after chronic exposure to $\mathrm{PM}_{1}$. CSF and serum inflammatory cytokines were examined for correlations with serum NEFL polypeptide levels to investigate the underlying mechanisms after chronic exposure to $\mathrm{PM}_{1}$.

\section{METHODS}

\section{Experimental Design}

Male 6-month-old Sprague Dawley (SD) rats obtained from the National Laboratory Animal Center (Taipei, Taiwan) were used throughout the study. Rats were randomly selected for three groups: high-efficiency particulate air (HEPA; exposed to gaseous pollution only; $n=12$; New Taipei City, Taiwan), and $\mathrm{PM}_{1}$ exposure to traffic-dominated air pollution (exposed to particulate and gaseous pollution; $n=12$; New Taipei City, Taiwan). The HEPA group (gaseous pollution only) served as control, whereas the $\mathrm{PM}_{1}$ (particulate and gaseous pollution) served as exposure. The exposure site was a traffic-dominant area, which was near a highway $(\sim 710 \mathrm{~m})$ and an expressway $(\sim 76 \mathrm{~m})$. The distance to the closest major road was approximately $62 \mathrm{~m}$. Rats were housed at a constant temperature of $22 \pm 2^{\circ} \mathrm{C}$ and a relative humidity (RH) of $55 \pm 10 \%$ with a 12:12-h light:dark cycle throughout the study. After 3 and 6 months of exposure, rats were necropsied, and serum and CSF were collected $(n=$ 6/group for 3 and 6 months; Li et al., 2009; Nirogi et al., 2009). Animal experiments were conducted in compliance with the animal and ethics review committee of the Laboratory Animal Center at Taipei Medical University (Taipei, Taiwan).

\section{Whole-body Exposure to $\mathrm{PM}_{1}$}

Rats were whole-body exposed to $\mathrm{PM}_{1}$ (particulate matter with an aerodynamic diameter of $<1 \mu \mathrm{m}$ ) using a wholebody exposure system for 3 and 6 months as previously reported (Shih et al., 2018). Data of the gaseous pollution were collected from the nearby Taiwan Environmental Protection Administration Yonghe air quality monitoring station, and the concentrations and physical properties of PM were characterized by the collocated instruments. In the system, a tapered element oscillating microbalance (TEOM; Model 1400a; Thermo Scientific, USA) was used to determine $\mathrm{PM}_{1}$ mass concentrations. A Scanning Mobility Particle Sizer (SMPS; Model 3936; TSI Inc., USA) and an Aerodynamic Particle Sizer (APS; Model 3321; TSI Inc., USA) were used to examine the submicron particle size distribution (PSD) and supermicron PSD, respectively. A Nanoparticle Surface Area Monitor (NSAM; Model 3550; TSI Inc., USA) was used to monitor lung deposition surface area (LDSA) concentrations. It was reported that measurements of black carbon (BC) by continuous monitors, such as an Aethalometer, showed good correlations with concentrations of traffic exhaust particles or with traffic counts (Wu et al., 2007; deCastro et al., 2008; Patel et al., 2009). Therefore, an Aethalometer (AE33; Magee Scientific, Berkeley, CA, USA) was used to measure the BC mass concentration. Additionally, the numbers of cars were manually calculated to obtain passenger car units (PCU) during the study period. 


\section{Enzyme-linked Immunosorbent Assay (ELISA)}

The NEFL polypeptide was determined in serum using an ELISA kit (Bioassay Technology Laboratory, Shanghai, China) in accordance with the manufacturer's instructions.

\section{Multiplex Assay for Serum}

IL-4, IL-6, IL-10, and tumor necrosis factor (TNF)- $\alpha$ in serum samples were determined by an AimPlex ${ }^{\mathrm{TM}}$ multiplex assay (St. Louis, MO, USA), according to the manufacturer's instructions. A BD LSRFortessa ${ }^{\mathrm{TM}}$ cell analyzer (NJ, USA) was used to determine complexes of beads and the studied proteins labeled with phycoerythrin antibodies.

\section{Cytometric Bead Array (CBA) for CSF}

Levels of IL-2, IL-4, IL-6, IL-10, IL-17A, interferon (IFN) $-\gamma$, and TNF- $\alpha$ in CSF were examined by a CBA (BD Bioscience, CA, USA), according to the manufacturer's instructions. Complexes of beads were determined with a BD LSRFortessa $^{\mathrm{TM}}$ cell analyzer.

\section{Statistical Analysis}

A nonparametric Mann-Whitney $U$-test was used to examine the difference between groups. We defined as extreme outlier cytokine values ten times higher than the value of the $99^{\text {th }}$ percentile. There were no significant outliers identified from the samples. Pearson's correlation coefficient was used to examine correlations of biomarkers between serum and CSF. Statistical analyses were performed using GraphPad vers. 5 for Windows. The level of significance was set to $p<0.05$. Data are expressed as the mean \pm standard deviation (SD).

\section{RESULTS AND DISCUSSION}

\section{Chronic Exposure to $\mathrm{PM}_{1}$}

Exposure to Air pollution has been linked to increased risks of neurodegenerative diseases (Malek et al., 2015; Lee et al., 2019). To study NEFL polypeptide expression in serum after chronic exposure to $\mathrm{PM}_{1}$, an in vivo whole-body exposure system was established for chronic exposure to $\mathrm{PM}_{1}$. Traffic is one of the most prominent sources contributing to airborne PM in urban environments, and a trailer-type monitoring site was established which was located in a neighborhood of the two major crossing/commuting avenues in the Shuang Ho area (New Taipei City, Taiwan), a typical urban environment in Taiwan. The average daily traffic flows in these major commuting routes are all over 50,000 PCU day ${ }^{-1}$. The average daily traffic volume was 444 cars $^{-1}$ and 4731 motorcycles $h^{-1}$ for evening rush hour (17:00-20:00) and $462 \mathrm{cars} \mathrm{h}^{-1}$ and 2183 motorcycles $\mathrm{h}^{-1}$ for morning rush hour (06:00-08:00) (Supplementary Material Fig. S1).

Sampling inlets were located at the top of the roof of the trailer station at about $6 \mathrm{~m}$ above the ground. The sampled traffic-related air pollution was delivered to two modified individual ventilated cage (IVC) systems. Rats were wholebody exposed to $\mathrm{PM}_{1}$ using a whole-body exposure system for 6 months as reported previously (Shih et al., 2018). One system with filters was considered exposure to gaseous pollutants only, and the other system without filters was the experimental group that was exposed to $\mathrm{PM}_{1}$ as well as gaseous pollutants. As shown in Fig. 1, the penetration of particles in the IVC without a filter was $75 \%$ over the entire particle size range, and the average particle penetration was $80 \%$ for particles of $<550 \mathrm{~nm}$ in size. In the particle size ranging 550-1000 nm, the average particle penetration was $34 \%$ and gradually decreased to about $20 \%$. In other words, the major particles to which the mice were exposed were $\mathrm{PM}_{1}$. For the IVC with filters, the average penetration of particles was $4 \%$ over the entire particle size range. Particularly for particles of > $600 \mathrm{~nm}$, the overall removal efficiency of particles could be as high as $99 \%$. The typical exposure PSDs measured in the exposure chamber/cabinet of the IVC are shown as a number and on a mass basis (Figs. 2(a) and 2(b)). The number PSD demonstrates the typical single Aitken-mode traffic characteristics with a major peak size of around $49 \mathrm{~nm}$ and a total number concentration of around $10^{4}-10^{5}$ particles $\mathrm{cm}^{-3}$. When an identical PSD was shown in the volume concentration, the typical tri-mode for $\mathrm{PM}_{1}$ was observed, and the peak size of the volume PSD was located at $400 \mathrm{~nm}$. Thus, the total mass concentration of $\mathrm{PM}_{1}$ should largely be attributed to these accumulation modes, and the main chemical components could be sulfate, nitrate, ammonium, organic carbon, elemental carbon, and heavy metals (Tsai et al., 2012; Liang et al., 2013; Lin et al., 2015).

Table 1 shows the air pollution to which rats were exposed during the study period. The $\mathrm{PM}_{1}, \mathrm{PNC}, \mathrm{BC}$, and LDSA were $16.3 \pm 8.2 \mu \mathrm{g} \mathrm{m}^{-3}, 11,257 \pm 4388$ particles $\mathrm{cm}^{-3}$,

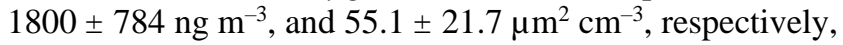
which were previously reported (Shih et al., 2018). In the present study, the rats were exposed to relatively lower levels of $\mathrm{PM}_{1}$ than the WHO $\mathrm{PM}_{2.5}$ guideline $\left(25 \mu \mathrm{g} \mathrm{m}^{-3}\right.$ for a 24-h average) (WHO, 2006). The PNC and BC presented higher levels during the experiment period than previous measurements (Chuang et al., 2017). This observation suggested that traffic-related particulate pollutants were the main source of exposure for rats. As to pollutants obtained from the air quality station, the $\mathrm{PM}_{10}, \mathrm{PM}_{2.5}, \mathrm{NO}_{x}, \mathrm{SO}_{2}$, and $\mathrm{O}_{3}$ levels were all below WHO guidelines (WHO, 2006). Therefore, the exposure conditions provided a good environment to study the effects of long-term exposure to lower levels of air pollution on neurotoxicity in vivo.

\section{Biomarkers Determined in Serum}

Systemic inflammation occurring after chronic exposure to air pollution was previously reported (Neophytou et al., 2013; Lee et al., 2016). In the present study, we determined levels of IL-4, IL-6, IL-10, TNF- $\alpha$, and the NEFL polypeptide in serum of rats after 3 and 6 months of exposure to $\mathrm{PM}_{1}$ (Fig. 3). We observed that IL-4, IL-10, and TNF- $\alpha$ significantly $(p<0.05)$ increased with 3 months of exposure to $\mathrm{PM}_{1}$. We observed that immune responses of IL-4 and TNF- $\alpha$ were activated after 3 months of $\mathrm{PM}_{1}$ exposure. Consistently, a study by Shakya et al. (2019) showed that levels of IL-4, IL-10, and TNF- $\alpha$ in the blood of humans were elevated after roadside exposure. Our previous study observed that air pollution activated an immune response in pneumonia (Bai et al., 2019b). Also, $\mathrm{PM}_{2.5}$ exposure increased the risk of pneumonia in patients with chronic obstructive 

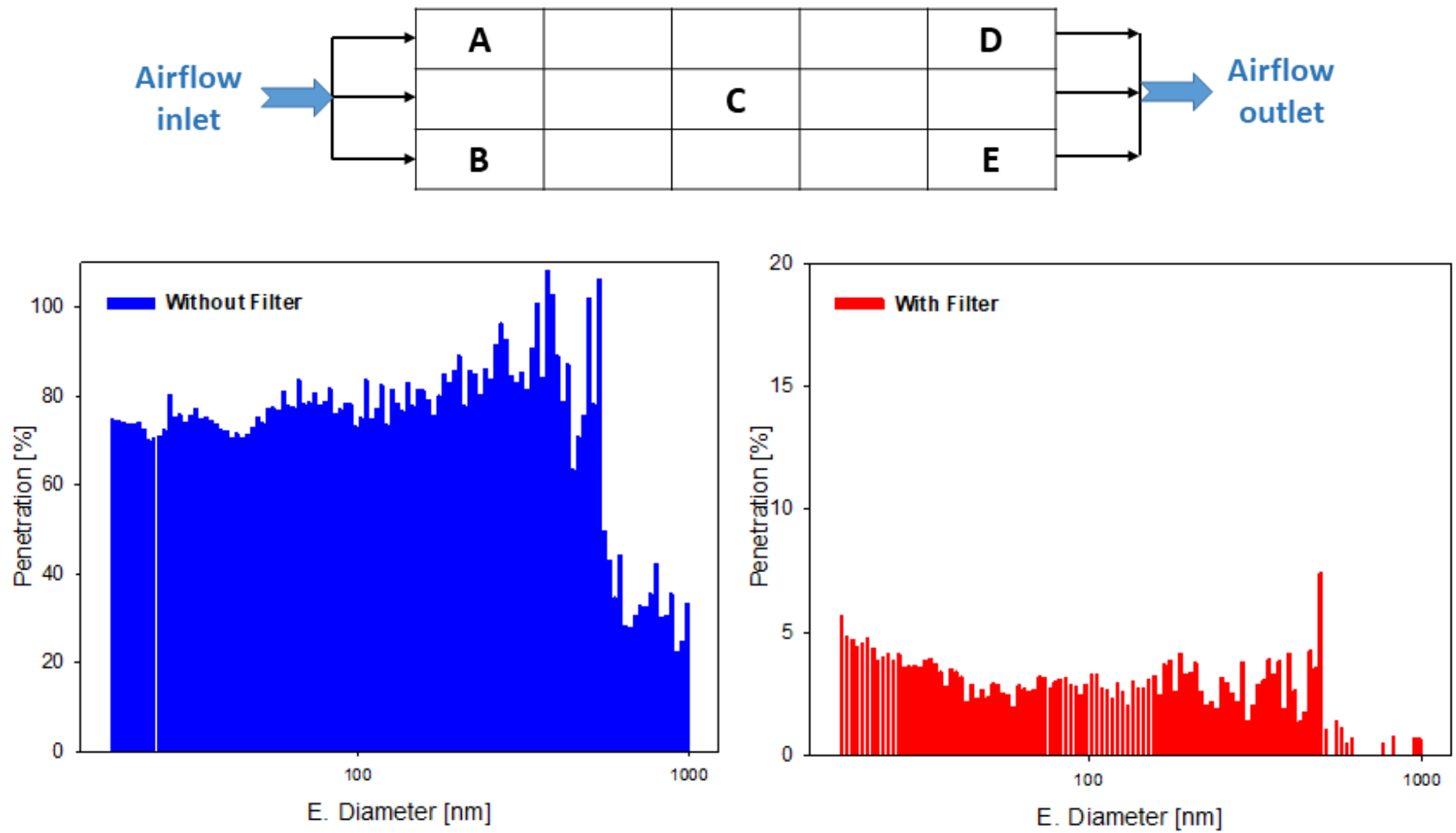

Fig. 1. Illustration of the airflow of the whole-body exposure system for the in vivo experiment. Average penetration rates of the filtered group and unfiltered group at different particle size ranges.
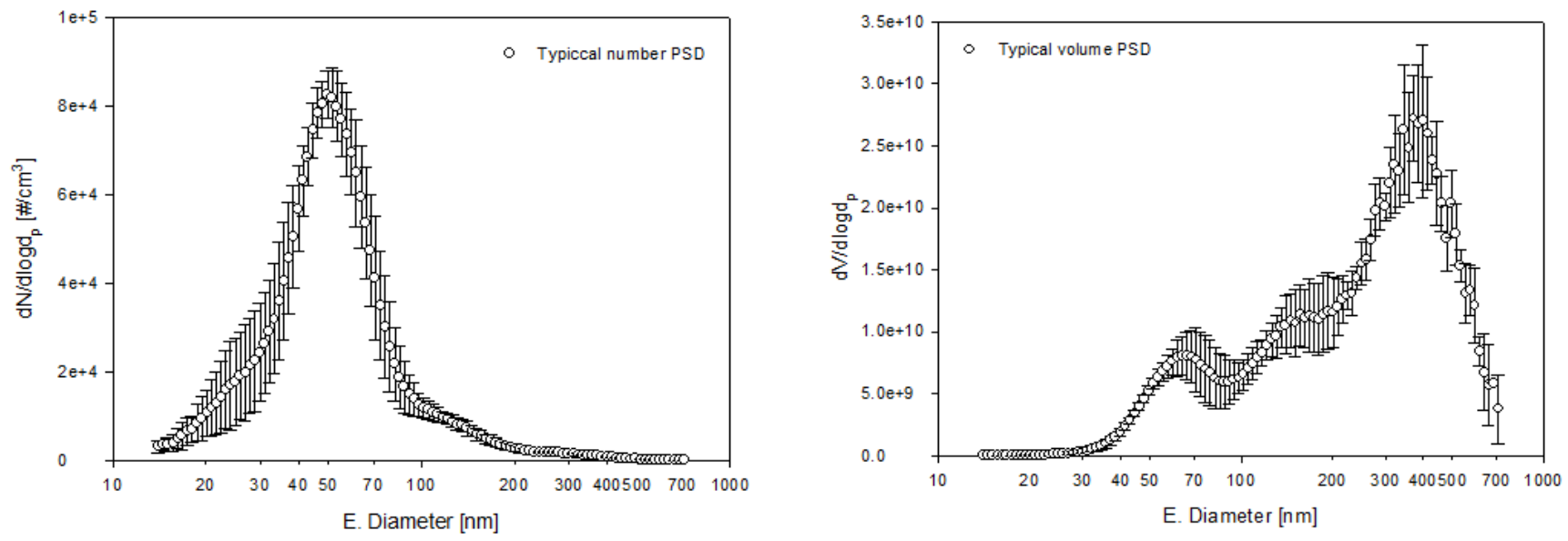

Fig. 2. (a) Typical exposure number particle size distribution (PSD); (b) typical exposure volume PSD.

pulmonary disease (COPD) (Ho et al., 2019). Therefore, $\mathrm{PM}_{1}$ exposure may alter systemic immune responses after subchronic exposure in rats.

We noted that serum IL-10 had increased after 3 months of $\mathrm{PM}_{1}$ exposure compared to the controls $(p<0.05)$, whereas there was no significant difference in IL-6 between the controls and the $\mathrm{PM}_{1}$-exposed group (Fig. 3). The results indicated that an anti-inflammatory reaction was activated to mitigate the $\mathrm{PM}_{1}$-induced systemic inflammation in rats. Inflammation was resolved by the self-repair/defense response; thus, persistent low-grade inflammation in serum after chronic exposure to $\mathrm{PM}_{1}$ was observed in our study. Notably, we investigated levels of the NEFL polypeptide in serum after $\mathrm{PM}_{1}$ exposure (Fig. 3). The NEFL polypeptide is unique to neuronal cells, and it is shed to the CSF and is detectable at low concentrations in peripheral blood (Disanto et al., 2017). The presence of increasing levels of the NEFL polypeptide in the CSF is considered to be an indicator of axonal damage in the CNS (Norgren et al., 2003). Recently, the NEFL polypeptide was detected in serum in the presence of a neurodegenerative disease (Norgren et al., 2003). Levels of the NEFL polypeptide showed good correlations between CSF and serum samples, both of which are able to represent the disease progress of neurodegenerative diseases (Disanto et al., 2017). In the present study, the NEFL polypeptide had significantly increased $(p<0.05)$ after 3 and 6 months of exposure to $\mathrm{PM}_{1}$ compared to the controls. Increased levels of the NEFL polypeptide suggested that chronic exposure to 
Table 1. Characterization of air pollution for whole-body exposure and ambient levels during the study period.

\begin{tabular}{cl}
\hline Meteorological and pollutants (unit) & Mean \pm SD \\
\hline Particulate matter $^{1}$ & \\
$\mathrm{PM}_{1}\left(\mu \mathrm{g} \mathrm{m}^{-3}\right)$ & $16.3 \pm 8.2$ \\
$\mathrm{PNC}\left(\mathrm{particles} \mathrm{cm}^{-3}\right)$ & $11,257 \pm 4388$ \\
$\mathrm{BC}\left(\mathrm{ng} \mathrm{m}^{-3}\right)$ & $1800 \pm 784$ \\
$\mathrm{LDSA}\left(\mu \mathrm{m}^{2} \mathrm{~cm}^{-3}\right)$ & $55.1 \pm 21.7$ \\
Ambient pollutants $^{2}$ & \\
$\mathrm{PM}_{10}\left(\mu \mathrm{g} \mathrm{m}^{-3}\right)$ & $36.6 \pm 15.2$ \\
$\mathrm{PM}_{2.5}\left(\mu \mathrm{g} \mathrm{m}^{-3}\right)$ & $19.7 \pm 9.8$ \\
$\mathrm{NO}_{x}(\mathrm{ppb})$ & $32.9 \pm 16.4$ \\
$\mathrm{SO}_{2}(\mathrm{ppb})$ & $2.5 \pm 1.0$ \\
$\mathrm{O}_{3}(\mathrm{ppb})$ & $29.7 \pm 11.0$ \\
\hline
\end{tabular}

${ }^{1}$ PM data referenced from Shih et al. (2018).

${ }^{2}$ Gaseous pollution was measured by the Environmental Protection Administration Yonghe air quality monitoring stations. $\mathrm{PM}_{1}$ : particulate matter of < $1 \mu \mathrm{m}$ in aerodynamic diameter; PNC: particle number concentration; BC: black carbon; LDSA: lung deposition surface area; $\mathrm{PM}_{10}$ : particulate matter of $<10 \mu \mathrm{m}$ in aerodynamic diameter; $\mathrm{PM}_{2.5}$ : particulate matter of $<2.5 \mu \mathrm{m}$ in aerodynamic diameter; $\mathrm{NO}_{2}$ : nitrogen dioxide; $\mathrm{SO}_{2}$ : sulfur dioxide; $\mathrm{O}_{3}$ : ozone.

$\mathrm{PM}_{1}$ led to an increase in its levels in the serum and CSF, which could be associated with the development of neurodegenerative diseases by $\mathrm{PM}_{1}$. However, more studies are required to investigate the role of the NEFL polypeptide in response to air pollution exposure.

\section{Biomarkers Determined in CSF}

CSF is commonly used to determine levels of neuroinflammation and oxidative stress and to represent the healthy or diseased statuses of the brain (Guest et al., 2014). In the present study, we observed that IL-17 $\mathrm{a}$ and TNF- $\alpha$ had increased with 3 months of $\mathrm{PM}_{1}$ exposure, and IL- 6 had increased with 6 months of $\mathrm{PM}_{1}$ exposure ( $p<0.05$; Fig. 4). Both 3 and 6 months of exposure to $\mathrm{PM}_{1}$ caused increases in IL-2, IL-10, and IFN- $\gamma$ levels in the CSF compared to the controls $(p<0.05$; Fig. 4). The results indicated that neuroinflammation occurred due to chronic exposure to $\mathrm{PM}_{1}$ as observed in the CSF. Similarly, alterations in CSF inflammatory markers due to air pollution were investigated in children and adults in Mexico City (Calderon-Garciduenas et al., 2016). They observed that $\mathrm{PM}_{2.5}$ exposure increased the risk of $\mathrm{AD}$ and $\mathrm{PD}$. A previous study further observed that neuroinflammation occurred in children of Mexico City after exposure to severe air pollution, leading to IL-6 and IL-2 increases in CSF (Calderon-Garciduenas et al., 2013). Smaller combustion-derived particles, especially ultrafine $\mathrm{PM}$, induced more-significant impacts in the brains of children (Gonzalez-Maciel et al., 2017). Therefore, alterations in inflammatory responses of CSF may be able to represent impairment of the brain caused by $\mathrm{PM}_{1}$. However, the contributions of physicochemistry of PM to CSF inflammation require further investigation.

\section{Correlations of Biomarkers between Serum and CSF}

CSF biomarkers were correlated with levels of inflammation in serum. In the present study, associations of biomarkers between serum and CSF were examined as shown in Table 2. We observed that serum TNF- $\alpha$ was correlated with serum NEFL polypeptide $(r=0.477, p<0.05)$. Serum IL-6 was correlated with CSF IL-2 $(r=0.520, p<0.01)$ and IL-10 $(r=0.478, p<0.05)$. Serum TNF- $\alpha$ was correlated with CSF IL-6 $(r=0.522, p<0.01)$, IL-17a $(r=0.519, p<0.01)$, TNF- $\alpha$ $(r=0.519, p<0.01)$, and IFN- $\gamma(r=0.407, p<0.05)$, whereas serum NEFL polypeptide was correlated with IL-2 $(r=0.529, p<0.01), \mathrm{IL}-4(r=0.571, p<0.01), \mathrm{IL}-6(r=$ $0.486, p<0.05)$, IL-10 $(r=0.653, p<0.01)$, IL-17a $(r=$ $0.683, p<0.01)$, TNF- $\alpha(r=0.683, p<0.01)$, and IFN- $\gamma(r$ $=0.596, p<0.01)$. The results indicated that immune responses and inflammatory markers were correlated between serum and CSF. Previous reports showed that CSF NEFL polypeptide was well correlated with serum levels (Norgren $e t$ al., 2003), which also increased after exposure to air pollution in the serum and CSF of children (Calderon-Garciduenas et al., 2016). Notably, we observed that serum NEFL polypeptide had good correlations with all markers determined in CSF (IL-2, IL-4, IL-6, IL-10, IL-17a, TNF- $\alpha$, and IFN- $\gamma$ ). Our observations suggest that serum NEFL polypeptide levels are a good biomarker to represent immune-inflammatory responses in CSF that occur due to $\mathrm{PM}_{1}$ exposure.

We next found that most of the markers were correlated with each other in the CSF in the present study, except for IL-2 with IL-17a, IL-2 with TNF- $\alpha$, and IL-5 with IL-10 (Table 2). These results suggest that a series of immuneinflammatory reactions were activated in the CSF after $\mathrm{PM}_{1}$ exposure in rats. Neuroinflammatory responses play a role in regulation of defense or damage reactions. Inhaled pollutants can damage epithelial and endothelial barriers in the lungs, allowing their movement to the brain, which would be a robust trigger of tight junction and neural antibodies. After exposure, the produced molecules may be able to activate autoimmune responses, which potentially would contribute to neuroinflammation and the pathological hallmarks of neurodegenerative diseases (Calderon-Garciduenas et al., 2015). $\mathrm{PM}_{2.5}$ is able to directly and/or indirectly induce brain inflammation. More evidence is required to understand the underlying mechanisms of neuroinflammation and brain injury caused by PM. 

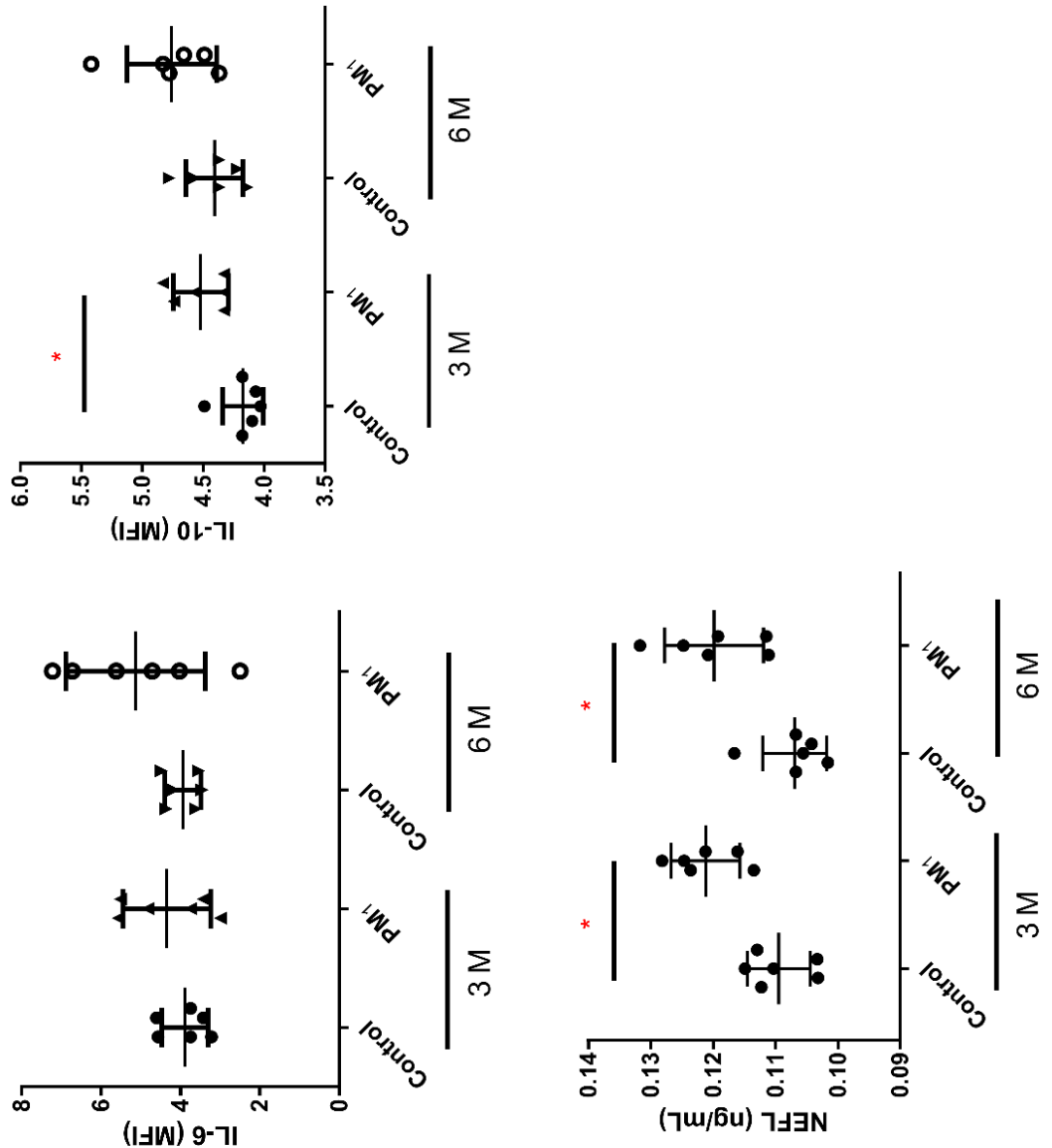

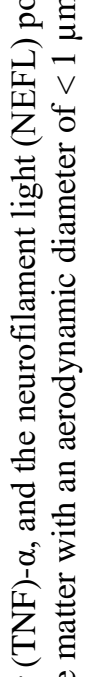
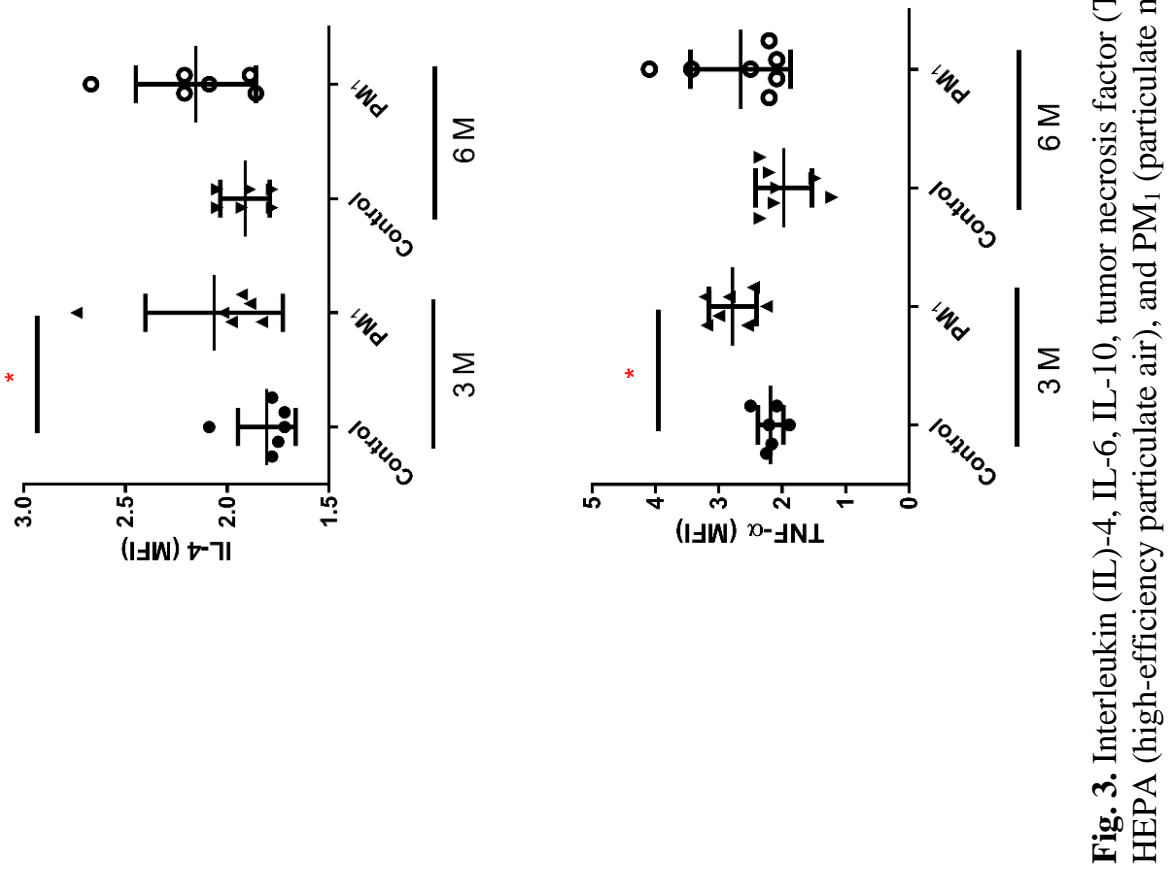

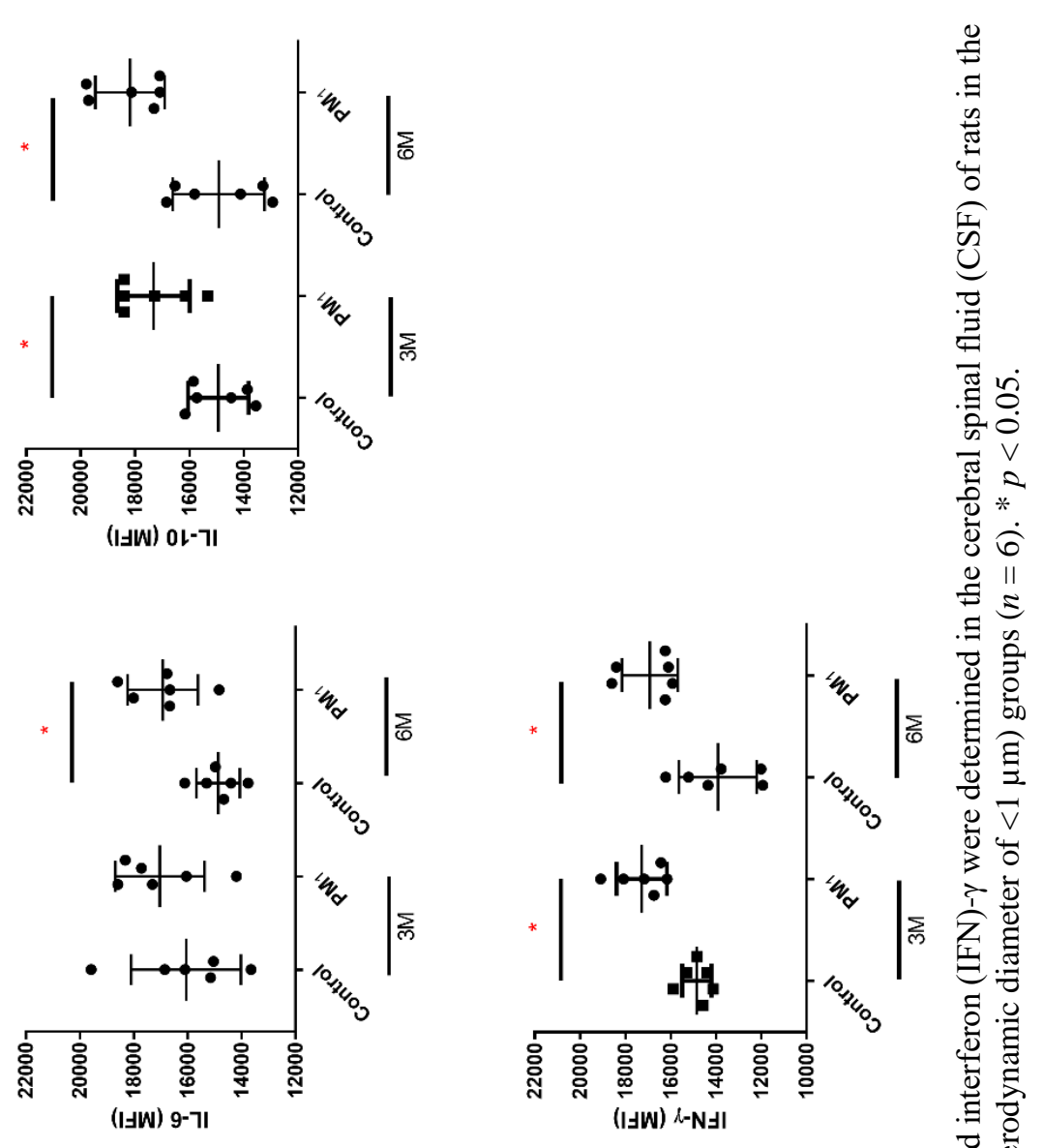

$\stackrel{2}{\Xi} \stackrel{11}{\Xi}$

$\Xi \underset{0}{\Xi}$

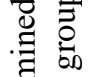

远

v $\vec{v}$

30

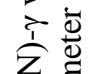

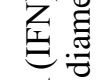

苋.

匍

(IJW) $\lambda$-N 1 l

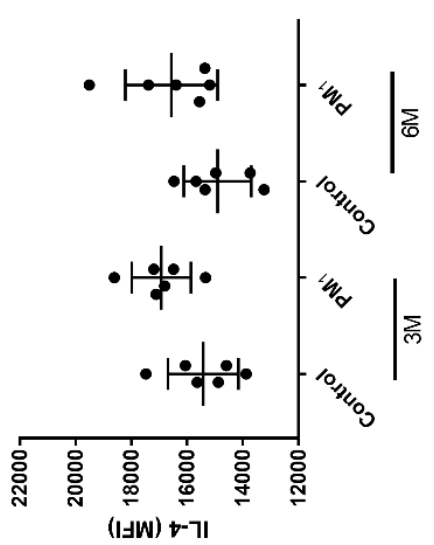

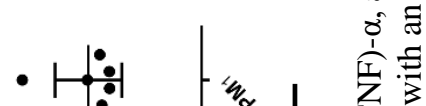

- 更 名

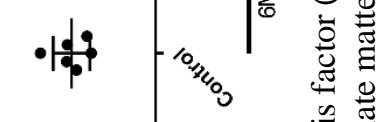

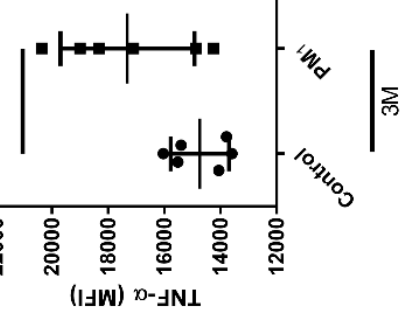

गु
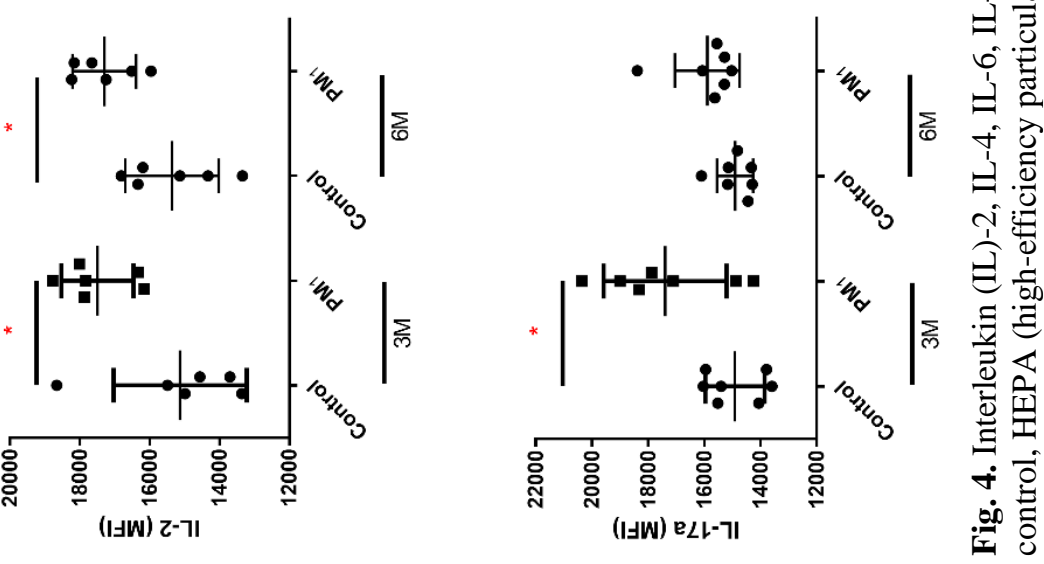
Table 2. Correlations of biomarkers between the serum and cerebral spinal fluid (CSF).

\begin{tabular}{|c|c|c|c|c|c|c|c|c|c|c|c|c|c|}
\hline & \multicolumn{5}{|c|}{ Serum } & \multicolumn{7}{|c|}{ CSF } \\
\hline & & IL-4 & IL-6 & IL-10 & TNF- $\alpha$ & NEFL & IL-2 & IL-4 & IL-6 & IL-10 & IL-17a & TNF- $\alpha$ & IFN- $\gamma$ \\
\hline$\Xi$ & IL-4 & 1.000 & 0.103 & 0.222 & 0.093 & 0.260 & 0.337 & 0.378 & 0.292 & 0.284 & 0.033 & 0.033 & 0.355 \\
\hline 党 & IL-6 & & 1.000 & 0.160 & 0.231 & 0.381 & $0.520^{* *}$ & 0.337 & 0.310 & $0.478^{*}$ & 0.263 & 0.263 & 0.170 \\
\hline & IL-10 & & & 1.000 & 0.292 & 0.210 & 0.179 & 0.253 & 0.290 & 0.371 & 0.313 & 0.313 & 0.356 \\
\hline & TNF- $\alpha$ & & & & 1.000 & $0.477^{*}$ & 0.357 & 0.268 & $0.522^{* *}$ & 0.337 & $0.519^{* *}$ & $0.519^{* *}$ & $0.407^{*}$ \\
\hline & NEFL & & & & & 1.000 & $0.529^{* *}$ & $0.571^{* * *}$ & $0.486^{*}$ & $\mathbf{0 . 6 5 3}^{* * *}$ & $0.683^{* *}$ & $0.683^{* *}$ & $0.596^{* * *}$ \\
\hline$\frac{\pi}{\sim 2}$ & IL-2 & & & & & & 1.000 & $0.514^{*}$ & $0.590^{* *}$ & $0.635^{* *}$ & 0.354 & 0.354 & $0.644^{* * *}$ \\
\hline U & IL-4 & & & & & & & 1.000 & $0.428^{*}$ & 0.389 & $0.569^{* *}$ & $0.569^{* *}$ & $0.658^{* * *}$ \\
\hline & IL-6 & & & & & & & & 1.000 & $0.491^{*}$ & $0.518^{* *}$ & $0.518^{* *}$ & $0.610^{* * *}$ \\
\hline & IL-10 & & & & & & & & & 1.000 & $0.491^{*}$ & $0.491^{*}$ & $0.666^{* * *}$ \\
\hline & IL-17a & & & & & & & & & & 1.000 & $0.878^{* * *}$ & $0.635^{* * *}$ \\
\hline & TNF- $\alpha$ & & & & & & & & & & & 1.000 & $0.635^{* *}$ \\
\hline & IFN- $\gamma$ & & & & & & & & & & & & 1.000 \\
\hline
\end{tabular}

** Correlation is significant at the 0.01 level (2-tailed). ${ }^{*}$ Correlation is significant at the 0.05 level (2-tailed).

IL: interleukin; TNF: tumor necrosis factor; NEFL: neurofilament light polypeptide; IFN: interferon.

\section{CONCLUSIONS}

We successfully established a whole-body exposure system of natural exposure to respirable PM (i.e., $\mathrm{PM}_{1}$ ) to investigate chronic in vivo impacts. To assess the exposure conditions, the levels of $\mathrm{PM}_{1}$ were measured on-line. Our previous findings showed that chronic exposure to this pollutant caused short-term memory loss, brain edema, and neuroinflammation in rats. Microglia activation was also observed following exposure. The present study further demonstrates that systemic neuroinflammatory and immune responses occur in rats after chronic exposure to $\mathrm{PM}_{1}$. Our results suggest that chronic exposure to $\mathrm{PM}_{1}$ may play a larger role than gaseous pollutants in triggering neurotoxicity. Critically, NEFL polypeptide in serum may be a biomarker for this damage.

\section{ACKNOWLEDGMENTS}

This study was funded by the Ministry of Science and Technology of Taiwan (MOST 108-2314-B-038-093). Authors wholeheartedly thank Miss Yi-Ying Chen, Mr. Zhe-Wei Lin and Mr. Xiao-Yue Chen for technical assistance during this project.

\section{DISCLAIMER}

The authors declare that they have no conflicts of interest.

\section{SUPPLEMENTARY MATERIAL}

Supplementary data associated with this article can be found in the online version at http://www.aaqr.org.

\section{REFERENCES}

Bai, K.J., Chuang, K.J., Wu, S.M., Chang, L.T., Chang, T.Y. Ho, K.F. and Chuang, H.C. (2018). Effects of diesel exhaust particles on the expression of tau and autophagy proteins in human neuroblastoma cells. Environ. Toxicol.
Pharmacol. 62: 54-59. https://doi.org/10.1016/j.etap.2018. 06.007

Bai, K.J., Chuang, K.J., Chen, C.L., Jhan, M.K., Hsiao, T.C., Cheng, T.J., Chang, L.T., Chang, T.Y. and Chuang, H.C. (2019a). Microglial activation and inflammation caused by traffic-related particulate matter. Chem. Biol. Interact. 311: 108762. https://doi.org/10.1016/j.cbi.2019.108762

Bai, K.J., Chuang, K.J., Chen, J.K., Tsai, C.Y., Yang, Y.L., Chang, C.C., Chen, T.T., Lee, C.N., Feng, P.H., Chen, K.Y., Lee, K.Y., Su, C.L., Ho, S.C., Wu, S.M. and Chuang, H.C. (2019b). Alterations by air pollution in inflammation and metals in pleural effusion of pneumonia patients. Int. J. Environ. Res. Public Health 16: 705. https://doi.org/10.3390/ijerph16050705

Brown, R.C., Lockwood, A.H. and Sonawane, B.R. (2005). Neurodegenerative diseases: An overview of environmental risk factors. Environ. Health Perspect. 113: 1250-1256. https://doi.org/10.1289/ehp.7567

Cacciottolo, M., Wang, X., Driscoll, I., Woodward, N., Saffari, A., Reyes, J., Serre, M.L., Vizuete, W., Sioutas, C., Morgan, T.E., Gatz, M., Chui, H.C., Shumaker, S.A., Resnick, S.M., Espeland, M.A., Finch, C.E. and Chen, J.C. (2017). Particulate air pollutants, APOE alleles and their contributions to cognitive impairment in older women and to amyloidogenesis in experimental models. Transl Psychiatry 7: e1022. https://doi.org/10.1038/tp.2016.280

Calderon-Garciduenas, L., Cross, J., Franco-Lira, M., Aragon-Flores, M., Kavanaugh, M., Torres-Jardon, R., Chao, C.K., Thompson, C., Chang, J., Zhu, H. and D'Angiulli, A. (2013). Brain immune interactions and air pollution: macrophage inhibitory factor (MIF), prion cellular protein $(\operatorname{PrP}(\mathrm{C}))$, Interleukin-6 (IL-6), interleukin 1 receptor antagonist (IL-1Ra), and interleukin-2 (IL-2) in cerebrospinal fluid and MIF in serum differentiate urban children exposed to severe vs. low air pollution. Front. Neurosci. 7: 183. https://doi.org/10.3389/fnins.2013.00183

Calderon-Garciduenas, L., Vojdani, A., Blaurock-Busch, E., Busch, Y., Friedle, A., Franco-Lira, M., SarathiMukherjee, P., Martinez-Aguirre, X., Park, S.B., TorresJardon, R. and D'Angiulli, A. (2015). Air pollution and 
children: neural and tight junction antibodies and combustion metals, the role of barrier breakdown and brain immunity in neurodegeneration. J. Alzheimers Dis. 43: 1039-1058. https://doi.org/10.3233/JAD-141365

Calderon-Garciduenas, L., Avila-Ramirez, J., CalderonGarciduenas, A., Gonzalez-Heredia, T., Acuna-Ayala, H., Chao, C.K., Thompson, C., Ruiz-Ramos, R., CortesGonzalez, V., Martinez-Martinez, L., Garcia-Perez, M.A., Reis, J., Mukherjee, P.S., Torres-Jardon, R. and Lachmann, I. (2016). Cerebrospinal fluid biomarkers in highly exposed $\mathrm{PM}_{2.5}$ urbanites: The risk of Alzheimer'S and Parkinson's diseases in young Mexico City residents. $J$. Alzheimers Dis. 54: 597-613. https://doi.org/10.3233/JAD160472

Calderon-Garciduenas, L., Mukherjee, P.S., Waniek, K., Holzer, M., Chao, C.K., Thompson, C., Ruiz-Ramos, R., Calderon-Garciduenas, A., Franco-Lira, M., ReynosoRobles, R., Gonzalez-Maciel, A. and Lachmann, I. (2018). Non-phosphorylated tau in cerebrospinal fluid is a marker of Alzheimer's disease continuum in young urbanites exposed to air pollution. J. Alzheimers Dis. 66: 1437-1451. https://doi.org/10.3233/JAD-180853

Chuang, H.C., Lin, Y.J., Chou, C.C.K., Hwang, J.S., Chen, C.C., Yan, Y.H., Hsieh, H.I., Chuang, K.J. and Cheng, T.J. (2017). Alterations in cardiovascular function by particulate matter in rats using a crossover design. Environ. Pollut. 231: 812-820. https://doi.org/10.1016/j.envpol.2017.08.082

deCastro, B.R., Wang, L., Mihalic, J.N., Breysse, P.N., Geyh, A.S. and Buckley, T.J. (2008). The longitudinal dependence of black carbon concentration on traffic volume in an urban environment. J. Air Waste Manage. Assoc. 58: 928939. https://doi.org/10.3155/1047-3289.58.7.928

Disanto, G., Barro, C., Benkert, P., Naegelin, Y., Schädelin, S., Giardiello, A., Zecca, C., Blennow, K., Zetterberg, H., Leppert, D., Kappos, L., Gobbi, C. and Kuhle, J. (2017). Serum Neurofilament light: A biomarker of neuronal damage in multiple sclerosis. Ann. Neurol. 81: 857-870. https://doi.org/10.1002/ana.24954

Gonzalez-Maciel, A., Reynoso-Robles, R., Torres-Jardon, R., Mukherjee, P.S. and Calderon-Garciduenas, L. (2017). Combustion-Derived nanoparticles in key brain target cells and organelles in young urbanites: Culprit hidden in plain sight in Alzheimer's disease development. J. Alzheimers Dis. 59: 189-208. https://doi.org/10.3233/JAD-170012

Guest, J., Grant, R., Garg, M., Mori, T.A., Croft, K.D. and Bilgin, A. (2014). Cerebrospinal fluid levels of inflammation, oxidative stress and NAD+ are linked to differences in plasma carotenoid concentrations. J Neuroinflammation. 11: 117. https://doi.org/10.1186/1742-2094-11-117

Ho, S.C., Chuang, K.J., Lee, K.Y., Chen, J.K., Wu, S.M., Chen, T.T., Lee, C.N., Chang, C.C., Feng, P.H., Chen, K.Y., Su, C.L., Tsai, C.Y. and Chuang, H.C. (2019). Chronic obstructive pulmonary disease patients have a higher risk of occurrence of pneumonia by air pollution. Sci Total Environ. 677: 524-529. https://doi.org/10.1016/ j.scitotenv.2019.04.358

Kioumourtzoglou, M.A., Schwartz, J.D., Weisskopf, M.G., Melly, S.J., Wang, Y., Dominici, F. and Zanobetti, A. (2016). Long-term $\mathrm{PM}_{2.5}$ exposure and neurological hospital admissions in the northeastern United States. Environ. Health Perspect. 124: 23-29. https://doi.org/10.1289/ehp. 1408973

Kuhle, J., Nourbakhsh, B., Grant, D., Morant, S., Barro, C., Yaldizli, O., Pelletier, D., Giovannoni, G., Waubant, E. and Gnanapavan, S. (2017). Serum neurofilament is associated with progression of brain atrophy and disability in early MS. Neurology 88: 826-831. https://doi.org/10.121 2/WNL.0000000000003653

Lee, H., Kang, J.M., Myung, W., Choi, J., Lee, C., Na, D.L., Kim, S.Y., Lee, J.H., Han, S.H., Choi, S.H., Kim, S.Y., Cho, S.J., Yeon, B.K., Kim, D.K., Lewis, M., Lee, E.M., Kim, C.T. and Kim, H. (2019). E Exposure to ambient fine particles and neuropsychiatric symptoms in cognitive disorder: A repeated measure analysis from the CREDOS (Clinical Research Center for Dementia of South Korea) study. Sci Total Environ. 668: 411-418. https://doi.org/ 10.1016/j.scitotenv.2019.02.447

Lee, K.Y., Chiang, L.L., Ho, S.C., Liu, W.T., Chen, T.T., Feng, P.H., Su, C.L., Chuang, K.J., Chang, C.C. and Chuang, H.C. (2016). Associations of autophagy with lung diffusion capacity and oxygen saturation in severe COPD: Effects of particulate air pollution. Int. J. Chron. Obstruct. Pulmon. Dis. 11: 1569-1578. https://doi.org/10. 2147/COPD.S108993

Li, D., Zhang, R., Cui, L., Chu, C., Zhang, H., Sun, H., Luo, J., Zhou, L., Chen, L., Cui, J., Chen, S., Mai, B., Chen, S., Yu, J., Cai, Z., Zhang, J., Jiang, Y., Aschner, M., Chen, R., Zheng, Y. and Chen, W. (2019). Multiple organ injury in male C57BL/6J mice exposed to ambient particulate matter in a real-ambient PM exposure system in Shijiazhuang, China. Environ. Pollut. 248: 874-887. https://doi.org/10.1016/j.envpol.2019.02.097

Li, N., Wang, M., Bramble, L.A., Schmitz, D.A., Schauer, J.J., Sioutas, C., Harkema, J.R. and Nel, A.E. (2009). The adjuvant effect of ambient particulate matter is closely reflected by the particulate oxidant potential. Environ. Health Perspect. 117: 1116-1123. https://doi.org/10.1289/ ehp.0800319

Liang, C.S., Yu, T.Y., Chang, Y.Y., Syu, J.Y. and Lin, W.Y. (2013). Source apportionment of $\mathrm{PM}_{2.5}$ particle composition and submicrometer size distribution during an Asian dust storm and non-dust storm in Taipei. Aerosol Air Qual. Res. 13: 545-554. https://doi.org/10.4209/aaqr. 2012.06.0161

Lin, G.Y., Lee, G.R., Lin, S.F., Hung, Y.H., Li, S.W., Wu, G.J., Ye, H., Huang, W. and Tsai, C.J. (2015). Ultrafine particles and $\mathrm{PM}_{2.5}$ at three urban air monitoring stations in northern Taiwan from 2011 to 2013. Aerosol Air Qual. Res. 15: 2305-2319. https://doi.org/10.4209/aaqr.2015.04. 0271

Liu, W.M., Wu, R.M., Lin, J.W., Liu, Y.C., Chang, C.H. and Lin, C.H. (2016). Time trends in the prevalence and incidence of Parkinson's disease in Taiwan: A nationwide, population-based study. J. Formos. Med. Assoc. 115: 531-538. https://doi.org/10.1016/j.jfma.2015.05.014

Malek, A.M., Barchowsky, A., Bowser, R., HeimanPatterson, T., Lacomis, D., Rana, S., Ada, Y. and Talbott, E.O. (2015). Exposure to hazardous air pollutants and the 
risk of amyotrophic lateral sclerosis. Environ. Pollut. 197: 181-186. https://doi.org/10.1016/j.envpol.2014.12.010

Molinuevo, J.L., Blennow, K., Dubois, B., Engelborghs, S., Lewczuk, P., Perret-Liaudet, A., Teunissen, C.E. and Parnetti, L. (2014). The clinical use of cerebrospinal fluid biomarker testing for Alzheimer's disease diagnosis: a consensus paper from the Alzheimer's Biomarkers Standardization Initiative. Alzheimers Dement. 10: 808817. https://doi.org/10.1016/j.jalz.2014.03.003

Neophytou, A.M., Hart, J.E., Cavallari, J.M., Smith, T.J., Dockery, D.W., Coull, B.A., Garshick, E. and Laden, F. (2013). Traffic-related exposures and biomarkers of systemic inflammation, endothelial activation and oxidative stress: A panel study in the US trucking industry. Environ Health 12: 105. https://doi.org/10.1186/1476069X-12-105

Nirogi, R., Kandikere, V., Mudigonda, K., Bhyrapuneni, G., Muddana, N., Saralaya, R. and Benade, V. (2009). A simple and rapid method to collect the cerebrospinal fluid of rats and its application for the assessment of drug penetration into the central nervous system. J. Neurosci. Methods 178: 116-119. https://doi.org/10.1016/j.jneume th.2008.12.001

Norgren, N., Rosengren, L. and Stigbrand, T. (2003). Elevated Neurofilament Levels in Neurological Diseases. Brain Res. 987: 25-31. https://doi.org/10.1016/S00068993(03)03219-0

Patel, M.M., Chillrud, S.N., Correa, J.C., Feinberg, M., Hazi, Y., Kc, D., Prakash, S., Ross, J.M., Levy, D. and Kinney, P.L. (2009). Spatial and temporal variations in trafficrelated particulate matter at New York City high schools. Atmos. Environ. 43: 4975-4981. https://doi.org/10.1016/ j.atmosenv.2009.07.004

Pereira, J.B., Westman, E., Hansson, O. and Alzheimer's Disease Neuroimaging, I. (2017). Association between cerebrospinal fluid and plasma neurodegeneration biomarkers with brain atrophy in Alzheimer's disease. Neurobiol. Aging 58: 14-29. https://doi.org/10.1016/j.neu robiolaging.2017.06.002

Power, M.C., Weisskopf, M.G., Alexeeff, S.E., Coull, B.A., Spiro, A., III and Schwartz, J. (2011). Traffic-related air pollution and cognitive function in a cohort of older men. Environ. Health Perspect. 119: 682-687. https://doi.org/ 10.1289/ehp.1002767

Ritz, B., Lee, P.C., Hansen, J., Funch Lassen, C., Ketzel, M., Sorensen, M. and Raaschou-Nielsen, O. (2016). Trafficrelated air pollution and parkinson's disease in Denmark: A case-control study. Environ. Health Perspect. 124: 351-356. https://doi.org/10.1289/ehp.1409313
Shakya, K.M., Peltier, R.E., Zhang, Y. and Pandey, B.D. (2019). Roadside exposure and inflammation biomarkers among a cohort of traffic police in Kathmandu, Nepal. Int. J. Environ. Res. Public Health. 16: 377. https://doi.org/ 10.3390/ijerph16030377

Shih, C.H., Chen, J.K., Kuo, L.W., Cho, K.H., Hsiao, T.C., Lin, Z.W., Lin, Y.S., Kang, J.H., Lo, Y.C., Chuang, K.J., Cheng, T.J. and Chuang, H.C. (2018). Chronic pulmonary exposure to traffic-related fine particulate matter causes brain impairment in adult rats. Part. Fibre Toxicol. 245: 226-234. https://doi.org/10.1186/s12989-018-0281-1

Suwannasual, U., Lucero, J., McDonald, J.D. and Lund, A.K. (2018). Exposure to traffic-generated air pollutants mediates alterations in brain microvascular integrity in wildtype mice on a high-fat diet. Environ Res. 160: 449461. https://doi.org/10.1016/j.envres.2017.10.029

The Lancet Neurology (2018). Air Pollution and Brain Health: An Emerging Issue. Lancet Neurol. 17: 103. https://doi.org/10.1016/S1474-4422(17)30462-3

Tsai, J.H., Lin, J.H., Yao, Y.C. and Chiang, H.L. (2012). Size distribution and water soluble ions of ambient particulate matter on episode and non-episode days in southern Taiwan. Aerosol Air Qual. Res. 12: 263-274. https://doi.org/10.4209/aaqr.2011.10.0167

Vogelgsang, J., Wedekind, D., Bouter, C., Klafki, H.W. and Wiltfang, J. (2018). Reproducibility of Alzheimer's disease cerebrospinal fluid-biomarker measurements under clinical routine conditions. J. Alzheimers Dis. 62: 203-212. https://doi.org/10.3233/JAD-170793

Weuve, J., Puett, R.C., Schwartz, J., Yanosky, J.D., Laden, F. and Grodstein, F. (2012). Exposure to particulate air pollution and cognitive decline in older women. Arch. Intern. Med. 172: 219-227. https://doi.org/10.1001/archi nternmed.2011.683

World Health Organization WHO (2006). WHO Air quality guidelines for particulate matter, ozone, nitrogen dioxide and sulfur dioxide: Global update 2005: Summary of risk assessment. World Health Organization, Geneva. https://apps.who.int/iris/handle/10665/69477

Wu, C.F., Larson, T.V., Wu, S.Y., Williamson, J., Westberg, H.H. and Liu, L.J.S. (2007). Source apportionment of $\mathrm{PM}_{2.5}$ and selected hazardous air pollutants in Seattle. Sci. Total Environ. 386: 42-52. https://doi.org/10.1016/j.scito tenv.2007.07.042

Received for review, August 8, 2019 Revised, February 6, 2020 Accepted, March 19, 2020 